\title{
The impact of interior construction on the indoor environmental quality
}

\author{
Katarína Harčárová, Silvia Vilčeková \\ Technical University of Košice, Slovakia \\ Civil Engineering Faculty, Institute of Environmental Engineering \\ e-mail: katarina.harcarova@tuke.sk, silvia.vilcekova@tuke.sk
}

\begin{abstract}
The presented paper deals with the evaluation of the indoor environmental quality (IEQ) in two apartment units in different phases of interior construction. The first apartment is in the initial phase of an unfurnished apartment and the second in the final phase of a fully furnished apartment. The results of IEQ monitoring indicate that in terms of thermal-humidity microclimate, the required legislative limits were met and the differences between the unfurnished and the fully furnished apartment were minimal. Only the operative temperature values were not in the legislative range. The average particulate matter (PM) concentrations of the two representative fractions $\left(\mathrm{PM}_{2.5}\right.$ and $\left.\mathrm{PM}_{10}\right)$ were $21.10 \mu \mathrm{g} / \mathrm{m}^{3}$ and $564.72 \mu \mathrm{g} / \mathrm{m}^{3}$ for the unfurnished apartment and $4.67 \mu \mathrm{g} / \mathrm{m}^{3}$ and 68.15 $\mu \mathrm{g} / \mathrm{m}^{3}$ for the furnished apartment. The legislative limit of $50 \mu \mathrm{g} / \mathrm{m}^{3}$ for $\mathrm{PM}_{10}$ was therefore significantly exceeded, especially in the case of an unfurnished apartment in the initial phase. The average TVOC concentration expressed in toluene equivalents was $1955 \mu \mathrm{g} / \mathrm{m}^{3}$ in a furnished apartment and $910 \mu \mathrm{g} / \mathrm{m}^{3}$ in an unfurnished apartment. Both of these values exceeded Mølhave's recommended limit of $200 \mu \mathrm{g} / \mathrm{m}^{3}$. The presence of xylenes $\left(51.19 \mu \mathrm{g} / \mathrm{m}^{3}\right)$ and ethylbenzene $\left(17.27 \mu \mathrm{g} / \mathrm{m}^{3}\right)$ was detected in an unfurnished apartment. In addition to xylenes $\left(171.63 \mu \mathrm{g} / \mathrm{m}^{3}\right)$ and ethylbenzene $\left(79.25 \mu \mathrm{g} / \mathrm{m}^{3}\right)$, toluene $\left(78.34 \mu \mathrm{g} / \mathrm{m}^{3}\right)$ was also present in the furnished apartment. The concentrations of these compounds were below the legislative limits, except for ethylbenzene for which no legislative limits are set. The above results show that further surface treatment and furnishing of the apartment contribute to the increase of the VOC levels in the indoor environment. In the case of unfurnished apartment, workers are exposed not only to elevated concentrations of TVOC but also to elevated concentrations of $\mathrm{PM}_{10}$ and should therefore pay attention to the protection and safety of health during the work.
\end{abstract}

Key words: indoor environmental quality, residential building, sick building syndrome, interior construction

\section{Introduction}

People spend almost more than $90 \%$ of their time in the indoor environment, where they are exposed to harmful pollutants of various origins [1,2]. Volatile organic compounds (VOCs) are among the most serious pollutants occurring in the indoor environment. These compounds are monitored due to their negative effect on the human health. Some of them enter the indoor environment of buildings from outdoors, but most originate from internal sources. Increased 
presence of volatile organic compounds can be observed especially in newly built or renovated buildings $[3,4]$. The main sources of VOC in the interiors of newly built or renovated buildings are considered to be the building materials. Particularly during completion, the interior goes through various stages of construction, but it is seldom known in which of these stages the greatest release of VOCs occurs and, in particular, what substances not only building users but also the workers themselves can be exposed to. Up to now, only a few studies have been published dealing with the contamination of the indoor environment at various stages of interior construction. Almost all of these studies are focused on the evaluation of IEQ in terms of the presence of volatile organic compounds. In a study by Park et al. performed several measurements in a newly built apartment complex in Korea. Within these measurements, they found that furniture was the main source of toluene and formaldehyde emissions [5]. Ochs et al. state that door painting is responsible for high emissions of acetone and other carbonyl compounds [6]. Gallon et al. measured VOC concentrations during the six phases of construction on two sites. The results show that the IAQ depends not only on emissions from building materials, but is also closely related to the overall implementation process [7]. Liang et al. measured VOC concentrations during the five stages of construction of a new apartment and found that the concentrations of toluene, $\alpha$ pinene and ethylbenzene increased significantly after the installation of doors and doorframes. The concentrations of propylene glycol also increased after applying the paint to the walls and benzene after furnishing the apartment [8]. In his next study, Liang monitored VOCs during eight phases of construction in a residential block in Nanjing, China. In this case, the results showed that VOC concentrations were higher for the so-called phases of "dry" material (completed by a carpenter) as for phases of "wet" material (completed by a painter). Alkanes were abundant in every stage of construction [9].

Another group of pollutants present in the indoor environment is particulate matter. During construction, a large amount of particulate matter is produced, which can still persist in a new building for several weeks after its use. Nevertheless, little information is available on the contamination of indoor air with particulate matter during the interior construction phases. For this reason, the objective of this paper is to point out the extent to which selected phases of interior design affect the quality of the indoor environment. At the same time, it focuses on determining the exact PM and VOCs concentrations to which not only apartment users are exposed before moving in, but also the workers themselves during the implementation of interior construction. In addition to these two chemical parameters, this paper evaluates basic physical parameters such as temperature, relative humidity and air velocity.

\section{Description of the monitored object}

Monitoring of the indoor environmental quality was carried out in a newly built residential building, which is situated in eastern Slovakia in the recreational area of Strba (High Tatras). The building consists of a reinforced concrete structure. Measurements and air sampling were performed in two residential units at different phases of interior construction. The first apartment unit, located on the third floor, was in the initial unfurnished phase, in which the wall surfaces and ceiling were plastered by applying gypsum plaster. In the case of the second apartment unit, it was a furnished one-room apartment located on the second floor. A laminate floor was installed in this apartment and at the same time the wall surfaces and ceiling were 
treated with gypsum plaster and interior wall paint. The interior was equipped with basic furniture (bed, bedside table, closet, living room wall) and kitchen unit made of chipboard, whereas the living room was directly connected to the kitchen. Both monitored apartments are shown in Figure 1. The individual apartments are separated from each other by reinforced concrete load-bearing partitions as well as non-load-bearing acoustic plasterboard partitions. The apartments are equipped with aluminum balcony doors consisting of insulating safety triple glazing and fire and security entrance doors with a laminate surface.

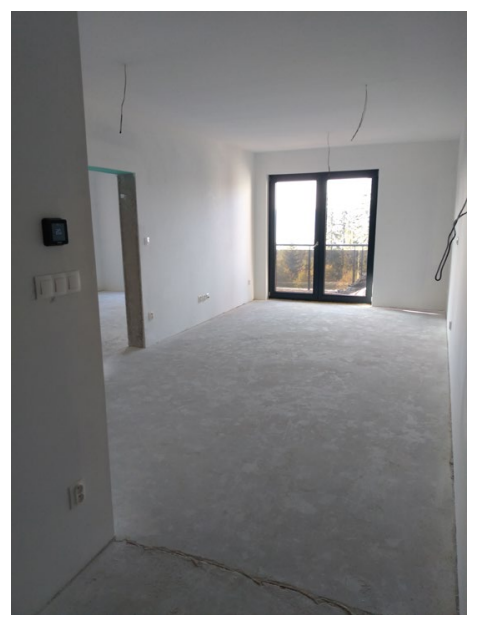

Apartment in initial stage

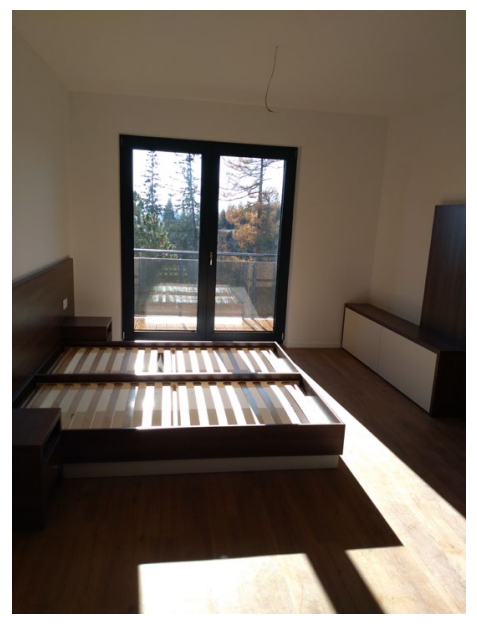

Apartment in final stage

Figure 1: Selected apartments in which indoor air monitoring was performed

\section{Method}

The parameters of the thermal-humidity microclimate (air temperature, relative humidity and air velocity) were determined using a TESTO 435-4 multifunction device with appropriate probe (Testo, Inc.; Germany). Particulate matter concentrations in the fraction range 0.5 to 10 $\mu \mathrm{m}\left(\mathrm{PM}_{0.5}-\mathrm{PM}_{10}\right)$ were determined using a HANDHELD 3016 IAQ meter (Lighthouse Worldwide Solutions, Inc., USA), which uses a laser-diode light source and collecting optics for particle detection. Total volatile organic compound (TVOC) concentrations were determined with a ppbRAE 3000 UV photoionization detector (RAE Systems, Inc.; USA). A two-point calibration, zero and standard reference gas (isobutylene), was performed before the measurement itself. All measured concentrations were recalculated and are expressed in toluene equivalents (correction factor stated by the manufacturer is 0.5 ). The probes and measuring instruments were placed approximately in the middle of the room at a height of approximately $1.1 \mathrm{~m}$ from the floor. The parameters of the thermal-humidity microclimate, particulate matter and total volatile organic compounds were recorded at one minute intervals. The mean radiant temperature at three heights was determined using a Vernon-Jokl spherical thermometer (sphere diameter $\mathrm{d}=0.1 \mathrm{~m}$ ) in accordance with the standard STN EN 7726, according to which the operative temperature was also calculated. Active sampling of the target volatile organic compounds was performed for six hours. The air samples were collected onto an Anasorb CSC sorption tube using an Airlite sampling pump. After 
sampling, the samples were further analyzed in an external laboratory by gas chromatography. Monitoring was performed in mid-September in the unheating period. Air exchange was not provided in the apartments during the entire monitoring. Measurements in the furnished apartment were performed approximately one month after the application of surface coatings and two weeks after the equipment of the apartment. In an unfurnished apartment, measurements were taken approximately one and a half months after the ceiling and walls were plastered.

\section{Results and Discussion}

The statistical evaluation of the measured data for both apartments is summarized in Table 1 . The above results were compared with the requirements for the thermal-humidity microclimate and the limit values of harmful factors in indoor air specified in the Decree of the Ministry of Health of the Slovak Republic No. 259/2008 and 210/2016 [10, 11].

Table 1: Statistical evaluation of measured data in apartments in two different phases of interior construction

\begin{tabular}{cccccccc}
\hline & Statistics & $\begin{array}{c}\text { Temperature } \\
{\left[{ }^{\circ} \mathrm{C}\right]}\end{array}$ & $\begin{array}{c}\text { Relative } \\
\text { humidity } \\
{[\%]}\end{array}$ & $\begin{array}{c}\text { Air } \\
\text { velocity } \\
{[\mathrm{m} / \mathrm{s}]}\end{array}$ & $\begin{array}{c}\mathrm{PM}_{2.5} \\
{\left[\mu \mathrm{g} / \mathrm{m}^{3}\right]}\end{array}$ & $\begin{array}{c}\mathrm{PM}_{10} \\
{\left[\mu \mathrm{g} / \mathrm{m}^{3}\right]}\end{array}$ & $\begin{array}{c}\mathrm{TVOC} \\
{\left[\mu \mathrm{g} / \mathrm{m}^{3}\right]}\end{array}$ \\
\hline Initial & Average & 19.76 & 61.09 & 0.00 & 21.10 & 564.72 & 910 \\
stage & Min & 19.37 & 59.95 & 0.00 & 17.50 & 244.02 & 509 \\
& Max & 20.14 & 61.69 & 0.23 & 24.32 & 907.42 & 1134 \\
& $\mathrm{SD}^{1}$ & 0.18 & 0.37 & 0.02 & 1.62 & 171.63 & 178.49 \\
Final & Average & 19.40 & 56.22 & 0.00 & 4.67 & 68.15 & 1955 \\
stage & Min & 18.97 & 52.13 & 0.00 & 3.88 & 43.85 & 1206 \\
& Max & 19.68 & 58.02 & 0.07 & 5.57 & 104.31 & 2407 \\
& $\mathrm{SD}{ }^{1}$ & 0.16 & 1.73 & 0.01 & 0.28 & 13.82 & 320.27 \\
\hline
\end{tabular}

${ }^{1}$ Standard deviation

\subsection{Thermal-humidity microclimate}

The average values of temperature and relative humidity measured in both apartment units did not differ significantly from each other. The difference between the average relative humidity in the apartment in the initial stage and in the apartment in the final stage was 5\%. The values of relative humidity in both apartments were within the required legislative range of $30-70 \%$. Figure 2 shows the temperature and relative humidity in the selected apartment units throughout the measurement period. In a furnished apartment, the values of relative humidity tended to increase continuously, while in the apartment in the initial stage they mostly fluctuated around one value. The measured values of the air velocity did not exceed the permissible legislative limit of $0 \leq 0.2 \mathrm{~m} / \mathrm{s}$ in any of the monitored apartments. The operating 
temperature in the unfurnished apartment was set at $19.4{ }^{\circ} \mathrm{C}$ and in the furnished apartment at $19{ }^{\circ} \mathrm{C}$. Both values were outside the legislatively optimal $\left(25-28^{\circ} \mathrm{C}\right)$ and permissible $(20-29$ ${ }^{\circ} \mathrm{C}$ ) range.

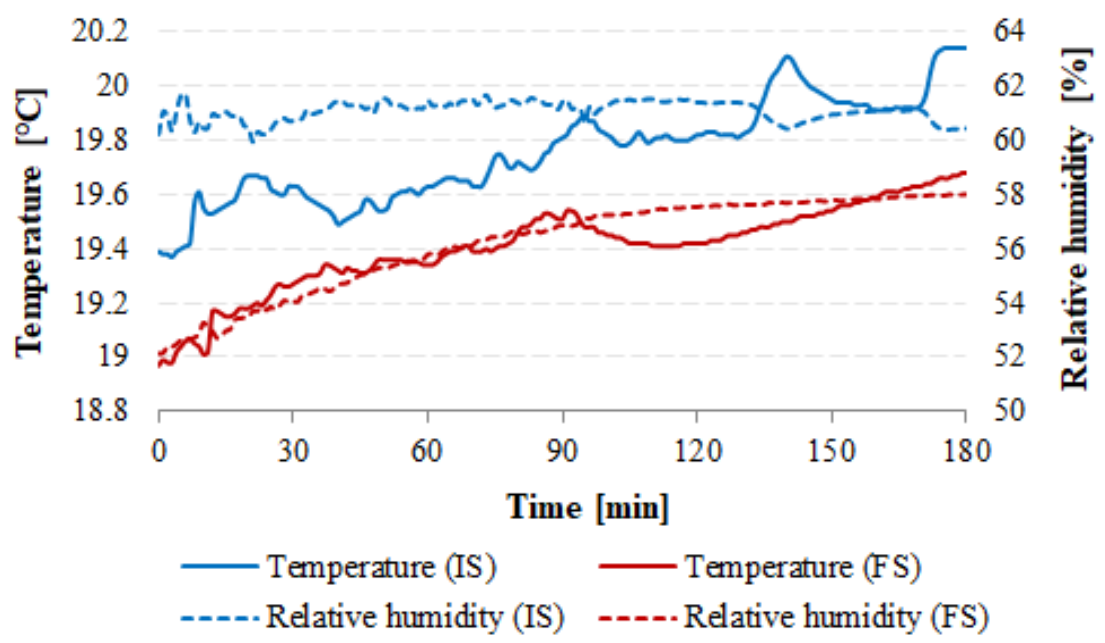

Figure 2: Recording of temperature and relative humidity measurements in the apartment in the initial stage (IS) and in the apartment in the final stage (FS) of interior construction

\subsection{PM concentrations}

The course of PM concentrations of all monitored fractions in the apartment in the initial stage and in the apartment in the final stage is shown in Figure 3. The difference between the maximum and minimum measured concentration was not higher than $1 \mu \mathrm{g} / \mathrm{m}^{3}$ in the case of fractions 0.5 and $1.0 \mu \mathrm{m}$ in none of the apartments. Particulate matter concentrations in the range $\mathrm{PM}_{2.5}-\mathrm{PM}_{10}$ already had a more fluctuating course. Apparently, fluctuations in $\mathrm{PM}_{5.0}$ and $\mathrm{PM}_{10}$ concentrations in the first half of the measurement were caused by the presence of two people in the room. In the second half of the measurement, a slow decrease in these concentrations was recorded, as monitoring was performed in the absence of people. The average concentrations of two representative fractions $\mathrm{PM}_{2.5}$ and $\mathrm{PM}_{10}$ in the furnished apartment reached the values of $4.67 \mu \mathrm{g} / \mathrm{m}^{3}$ and $68.15 \mu \mathrm{g} / \mathrm{m}^{3}$. Concentrations of $\mathrm{PM}_{2.5}$ ranged from $3.88 \mu \mathrm{g} / \mathrm{m}^{3}$ to $5.57 \mu \mathrm{g} / \mathrm{m}^{3}$ and $\mathrm{PM}_{10}$ concentrations from $43.85 \mu \mathrm{g} / \mathrm{m}^{3}$ to $104.31 \mu \mathrm{g} / \mathrm{m}^{3}$. The highest permissible value of $\mathrm{PM}_{10}$ concentrations is according to the Decree of the Ministry of Health of the Slovak Republic $50 \mu \mathrm{g} / \mathrm{m}^{3}$. In the case of this apartment unit, the limit value was exceeded by $27 \%$, as the measurement performed in a new building, in which interior construction works were still in progress. Conversely, in an unfurnished apartment, $\mathrm{PM}_{2.5}$ concentrations ranged from $17.50 \mu \mathrm{g} / \mathrm{m}^{3}$ to $24.32 \mu \mathrm{g} / \mathrm{m}^{3}$ and $\mathrm{PM}_{10}$ concentrations from $244.02 \mu \mathrm{g} / \mathrm{m}^{3}$ to $907.42 \mu \mathrm{g} / \mathrm{m}^{3}$. The average particulate matter concentration for the $\mathrm{PM}_{2.5}$ fraction was $21.10 \mu \mathrm{g} / \mathrm{m}^{3}$ and for $\mathrm{PM}_{10} 564.72 \mu \mathrm{g} / \mathrm{m}^{3}$. In this case, the limit value for $\mathrm{PM}_{10}$ was exceeded by up to $91 \%$. Although the apartment is not yet habitable at this stage of construction, it is important from a health point of view to know what concentrations of $\mathrm{PM}_{10}$ people can only be exposed to if they work in such an environment. During the presence of 
people in the room, the average concentration of $\mathrm{PM}_{10}$ in the unfurnished apartment was exceeded by $93 \%$ and in the furnished apartment by $37 \%$.

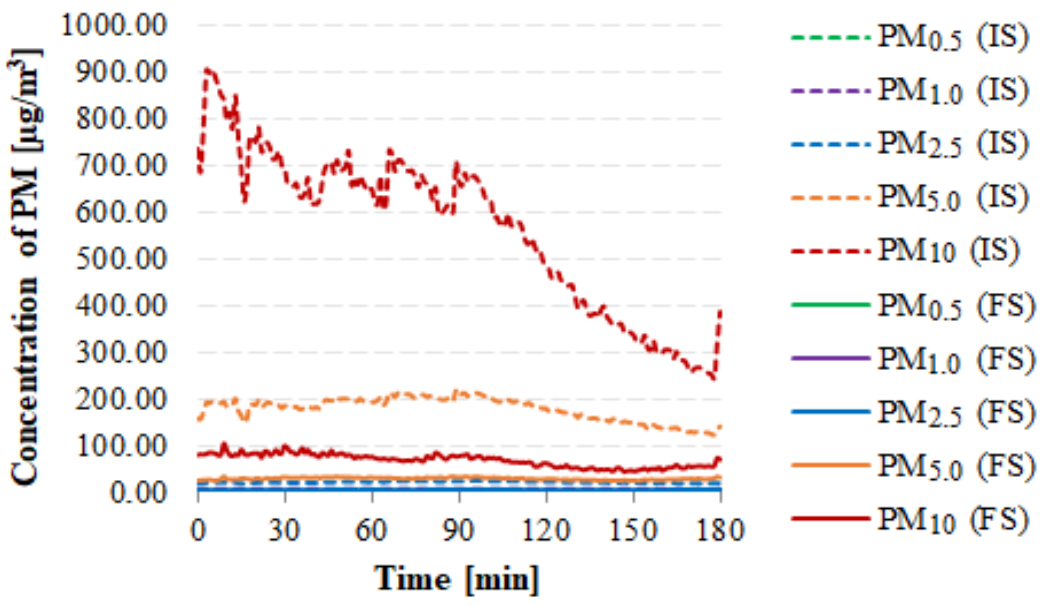

Figure 3: The course of $\mathrm{PM}_{0.5}-\mathrm{PM}_{10}$ concentrations in the apartment in the initial and final stage of interior construction

\subsection{VOC concentrations}

The figure 4 shows that TVOC concentrations had an increasing trend in both monitored units, as the windows and doors were closed throughout the measurement. The average TVOC concentration in a furnished apartment was $1955 \mu \mathrm{g} / \mathrm{m}^{3}$, which represents a $54 \%$ increase compared to the unfurnished apartment, in which the average TVOC concentration reached $910 \mu \mathrm{g} / \mathrm{m}^{3}$. The recommended concentration of TVOC $\left(200 \mu \mathrm{g} / \mathrm{m}^{3}\right)$ according to Mølhave [12], which does not yet cause discomfort or adverse health effects, was exceeded by $78 \%$ in the case of an unfurnished apartment and by $90 \%$ in the case of a furnished apartment.

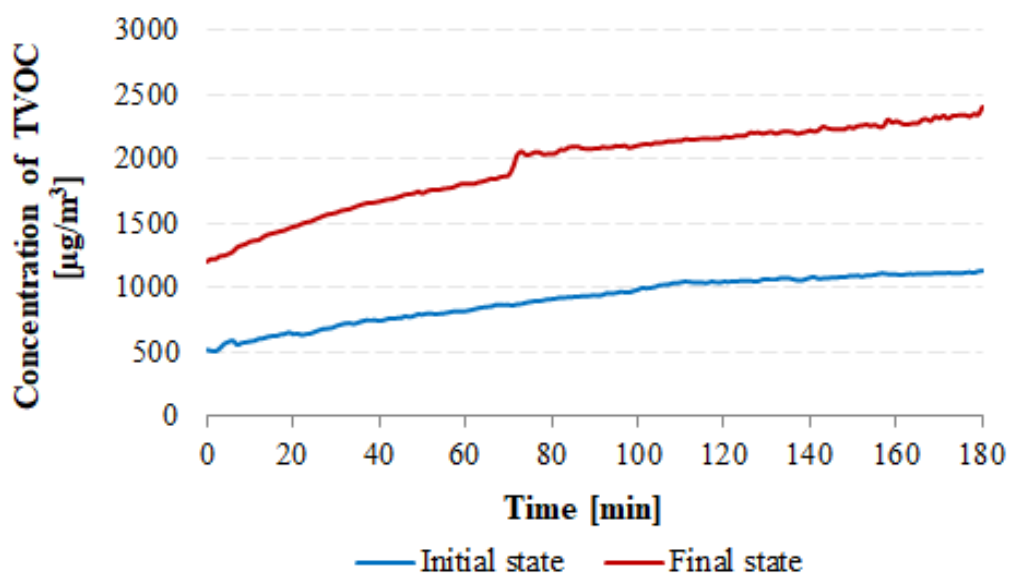

Figure 4: The course of TVOC concentrations in the apartment in the initial (IS) and final state (FS) of interior construction 
In addition to the determination of total volatile organic compounds, the identification and determination of target organic compounds listed in the Decree of the Ministry of Health of the Slovak Republic No. 259/2008 and 210/2016 was also performed. Exposure to elevated concentrations of these four priority organic compounds in the indoor environment of buildings, namely toluene, three xylenes, styrene and tetrachlorethylene, may have adverse effects on human health. The results of the analysis of selected VOCs for both phases of interior construction are stated in Table 2. Of these four compounds, only xylenes were present in the unfurnished apartment (initial stage of construction), the concentrations of which were below the legislative limit of $4800 \mu \mathrm{g} / \mathrm{m}^{3}$. In the furnished apartment (final stage of construction) the sum of three xylenes was $70.2 \%$ higher than in the unfurnished apartment, but it was still below the legislative limit. In addition, the presence of toluene was demonstrated in the furnished apartment. However, this concentration was also below the limit value of $8000 \mu \mathrm{g} / \mathrm{m}^{3}$. The presence of styrene and tetrachlorethylene was not confirmed in either of the monitored apartments, as the concentrations of these two substances were below the detection limits. In the case of an unfurnished apartment, these compounds may come from emissions from the plasterboard and the putty paste used in the installation of the plasterboard. It is also possible that these VOCs come from mounted doors. On the contrary, in a furnished apartment it is a bit more complicated to define specific sources of VOCs, because in this case VOCs can come not only from building materials, but also from furnishing.

In addition to the target VOCs, the presence of ethylbenzene was detected in both apartments. For ethylbenzene, the legislation does not specify its limiting concentration in the indoor environment of buildings, but long-term exposure to its increased concentrations may have irritating effects on the human body. Compared to the unfurnished apartment, its concentration in the furnished apartment was $78.2 \%$ higher. The most common sources of ethylbenzene in the indoor environment of buildings are wall materials [13].

Table 2: Determined concentrations of target VOCs

\begin{tabular}{lcc}
\hline & Initial stage & Final stage \\
\hline Toluene $\left[\mu \mathrm{g} / \mathrm{m}^{3}\right]$ & $<\mathrm{LOD}^{2}$ & 78.34 \\
Xylenes $\left[\mu \mathrm{g} / \mathrm{m}^{3}\right]$ & 51.19 & 171.63 \\
Styrene $\left[\mu \mathrm{g} / \mathrm{m}^{3}\right]$ & $<\mathrm{LOD}$ & $<\mathrm{LOD}$ \\
Tetrachloroethylene $\left[\mu \mathrm{g} / \mathrm{m}^{3}\right]$ & $<$ LOD & $<$ LOD \\
Ethylbenzene $\left[\mu \mathrm{g} / \mathrm{m}^{3}\right]$ & 17.27 & 79.25 \\
\hline${ }^{2}$ Limit of detection & &
\end{tabular}

\subsection{I/O ratios for PM2.5, PM10 and TVOC}

As the monitoring of priority pollutants was carried out in a new residential building, in which interior modifications were underway, it is clear that indoor sources will predominate in this building. To confirm this statement, measurements of outdoor air quality were also performed. The ratio of indoor and outdoor air pollutants ( $/ / O)$ is an important indicator for identifying the origin of different pollutants. Many methods for evaluating I/O ratios have 
been described $[13,14]$. In this study, I/O ratios were generated in a conventional way, where the outdoor air near the building is monitored simultaneously with the indoor air. A higher $\mathrm{I} / \mathrm{O}$ ratio value means a larger contribution from indoor sources. If $\mathrm{I} / \mathrm{O}<1$, the selected pollutants come from outdoor sources, if $\mathrm{I} / \mathrm{O}>1$ comes from indoor sources. Figure 5 shows that all monitored pollutants come from indoor sources, whether it is an unfurnished or a furnished apartment. However, a higher increase in TVOC and $\mathrm{PM}_{2.5}$ levels can be observed in the case of a furnished apartment. On the contrary, in the unfurnished apartment a significantly higher increase can be observed in terms of $\mathrm{PM}_{10}$ levels.

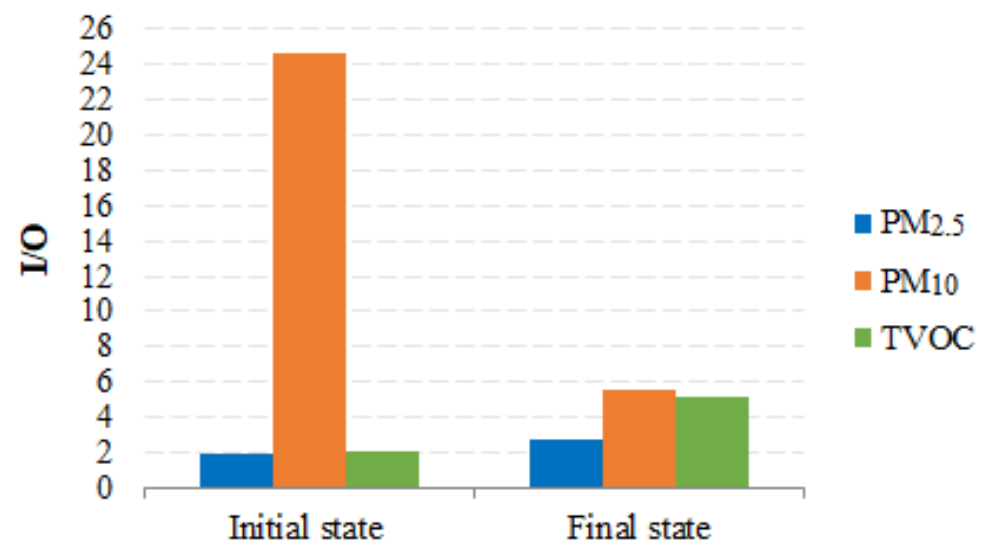

Figure 5: I/O ratios of selected pollutants

\section{Conclusion}

After evaluating the results, it can be stated that the resulting values of the thermal-humidity microclimate parameters were comparable for both apartments. At the same time, these values were within the required legislative limits, except for the operative temperature values. The average particulate matter concentrations of the two representative fractions $\left(\mathrm{PM}_{2.5}\right.$ and $\left.\mathrm{PM}_{10}\right)$ were significantly different for both apartments. In the case of an apartment in the initial stage, the permissible legislative limit of $\mathrm{PM}_{10}$ concentrations was exceeded several times, and therefore workers should pay attention to the protection and safety of health during further work in this apartment. Concentrations of TVOC exceeded Mølhave's recommended limit of $200 \mu \mathrm{g} / \mathrm{m}^{3}$ in both apartments. In a furnished apartment, the average TVOC concentration was up to half as high as in an unfurnished apartment. As part of VOC monitoring, a more detailed analysis of indoor air was performed, focused on the identification and determination of the four target VOCs (xylenes, toluene, tetrachlorethylene and styrene) listed in the Decree of the Ministry of Health of the Slovak Republic. Of these compounds, only xylenes were present in the unfurnished apartment. In addition to xylenes, toluene was also identified in the furnished apartment. The concentrations of all detected VOCs listed in the Decree of the Ministry of Health of the Slovak Republic were below the legislative limits. Simultaneously, the presence of ethylbenzene was detected in both flats, which is not subject to any legislative requirements. The presence of tetrachlorethylene and styrene was not confirmed in any of the apartments. Unambiguous identification of potential sources of detected VOCs is difficult in this case and requires an even more detailed 
examination of the individual interphases that the apartment goes through during construction. The fact that the pollution of the indoor environment in both units comes mainly from internal sources was also confirmed by the results of the evaluation of $\mathrm{I} / \mathrm{O}$ ratios. Monitoring of selected physico-chemical parameters of IEQ turned out for both stages of interior construction according to the assumptions with the possibility to quantify the exact concentrations of individual pollutants to which not only their new users but also the workers themselves may be exposed. It is assumed that even if the individual phases were evaluated within the same apartment, the results would probably not differ significantly from those mentioned in this paper.

\section{Acknowledgements}

This research was funded by VEGA grant agency with grant number 1/0512/20.

\section{References}

[1] Cakmak, S., Dales, R. E., Liu, L., Kauri, L. M., Lemieux, C. L., Hebbern, C., \& Zhu, J. (2014). Residential exposure to volatile organic compounds and lung function: results from a population-based cross-sectional survey. Environmental pollution, 194, 145-151.

[2] Yin, H., Liu, C., Zhang, L., Li, A., \& Ma, Z. (2019). Measurement and evaluation of indoor air quality in naturally ventilated residential buildings. Indoor and Built Environment, 28(10), 1307-1323.

[3] Földváry, V., Bekö, G., Langer, S., Arrhenius, K., \& Petráš, D. (2017). Effect of energy renovation on indoor air quality in multifamily residential buildings in Slovakia. Building and Environment, 122, 363-372.

[4] Du, L., Leivo, V., Prasauskas, T., Täubel, M., Martuzevicius, D., \& Haverinen-Shaughnessy, U. (2019). Effects of energy retrofits on Indoor Air Quality in multifamily buildings. Indoor air, 29(4), 686-697.

[5] Park, J. C., Kwon, Y. C., \& Jun, H. D. (2011). A study on the improvement of indoor air quality of newly-built apartment houses using low emission building materials. Journal of Asian Architecture and Building Engineering, 10(1), 235-240.

[6] de Mendonça Ochs, S., de Almeida Furtado, L., Cerqueira, W. V., \& Netto, A. D. P. (2016). Characterization of the variation of carbonyl compounds concentrations before, during, and after the renovation of an apartment at Niterói, Brazil. Environmental Science and Pollution Research, 23(15), 15605-15615.

[7] Gallon, V., Le Cann, P., Sanchez, M., Dematteo, C., \& Le Bot, B. (2020). Emissions of VOCs, SVOCs, and mold during the construction process: Contribution to indoor air quality and future occupants' exposure. Indoor air.

[8] Liang, W., Wang, C., Yang, C., \& Yang, X. (2014). Volatile organic compounds in different interior construction stages of an apartment. Building and environment, 81, 380-387.

[9] Liang, W. (2020). Volatile organic compounds, odor, and inhalation health risks during interior construction of a fully furnished residential unit in Nanjing, China. Building and Environment, 186, 107366.

[10] Ministry of Health, Slovak Republic, Governmental Regulation Number 259/2008 Coll. 2008. Detailed Requirements for the internal environment of buildings and on minimum requirements 
for apartments of lower standard and accommodation facilities.

[11] Ministry of Health, Slovak Republic, Governmental Regulation Number 210/2016 Coll. 2016. Detailed Requirements for Indoor Environment of Buildings and minimum Requirements for Low-standard Flats and Accommodation Facilities.

[12] Mølhave, L. (1991). Volatile organic compounds, indoor air quality and health. Indoor Air, 1(4), 357-376.

[13] Kozielska, B., Mainka, A., Żak, M., Kaleta, D., \& Mucha, W. (2020). Indoor air quality in residential buildings in Upper Silesia, Poland. Building and Environment, 106914.

[14] Xu, J., Szyszkowicz, M., Jovic, B., Cakmak, S., Austin, C. C., \& Zhu, J. (2016). Estimation of indoor and outdoor ratios of selected volatile organic compounds in Canada. Atmospheric Environment, 141, 523-531. 